\title{
Medication Safety in Intravenous Therapy: A Compatibility Study and Analysis of Reaction Products of Dihydralazine and Metamizole
}

\author{
Anna Katharina Koller ${ }^{1, \dagger}$, Oliver Fischer ${ }^{2, *,+}{ }^{\oplus}$, Sabine Krebs ${ }^{1}$, Markus R. Heinrich ${ }^{2}$ and \\ Frank Dörje ${ }^{1}$ \\ 1 Pharmacy Department, Erlangen University Hospital, Erlangen, Palmsanlage 3, 91054 Erlangen, Germany; \\ Anna-Katharina.Koller@uk-erlangen.de (A.K.K.); Sabine.Krebs@uk-erlangen.de (S.K.); \\ frank.doerje@uk-erlangen.de (F.D.) \\ 2 Department of Chemistry and Pharmacy, Pharmaceutical Chemistry, Friedrich-Alexander-Universität \\ Erlangen-Nürnberg, Nikolaus-Fiebiger-Strasse 10, 91058 Erlangen, Germany; markus.heinrich@fau.de \\ * Correspondence: oliver.fischer@fau.de; Tel.: +49-9131-85-65455 \\ + These authors contributed equally to this work.
}

Received: 23 April 2020; Accepted: 9 May 2020; Published: 18 May 2020

check for updates

\begin{abstract}
The pharmacotherapy of critically ill patients is challenging due to the variety of drugs that have to be applied. As the majority of pharmaceuticals must be administered intravenously because of the critical condition of the patients, the compatibility of co-applied intravenous drugs is crucial for a safe and successful infusion therapy. Antihypertensive therapy was reported by health care professionals to be ineffective in association with concomitant application of dihydralazine and metamizole (dipyrone). As both drugs are administered in German intensive care units, we analyzed their compatibility, examined the mechanisms of underlying dihydralazine degradation, and identified reaction products of dihydralazine and metamizole. Binary combinations were prepared at the high and the low end of the nominal administration concentration. Validated high performance liquid chromatography/ultraviolet absorption (HPLC-UV) analysis was conducted to quantify drug amount and high performance liquid chromatography/mass spectrometry (HPLC-MS) was used to analyze degradation products. The combinations of dihydralazine and metamizole proved to be incompatible as dihydralazine concentration decreased immediately and considerably. Metamizole also slightly decreased over time. Specific degradation products of dihydralazine were identified and a degradation pathway was postulated. Our findings demonstrate that the intravenous co-administration of dihydralazine and metamizole should be strictly avoided due to the incompatibility of these two drugs.
\end{abstract}

Keywords: infusion therapy; medication safety; Y-site compatibility; dihydralazine; metamizole; HPLC-UV; HPLC-MS

\section{Introduction}

Dihydralazine is a potent peripheral vasodilator and antihypertensive agent used for the treatment of hypertension [1,2]. Patients with severe hypertension and pulmonary hypertension in intensive care units particularly benefit from its administration. Alongside dihydralazine, patients often receive a considerable number of additional drugs, e.g., analgetic agents such as metamizole (dipyrone), so the intravenous compatibility of the drugs applied is essential for a safe and effective pharmacotherapy [3-7]. Currently, little is known about the compatibility of dihydralazine. As it is an arylhydrazine derivative, it is highly reactive towards other agents. However, neither the summary of product characteristics of dihydralazine nor existing publications provide sufficient information on Y-site compatibility 
with other concomitantly applied intravenous drugs. As intensive care units empirically reported a decreasing effect of dihydralazine during its frequent co-administration with metamizole. Therefore, we designed and conducted a compatibility study including HPLC-UV and HPLC-MS analytics of clinically relevant concentration ranges to investigate the compatibility of this binary combination. To our knowledge, no information on the compatibility of dihydralazine and metamizole is available in the international literature.

\section{Materials and Methods}

\subsection{Sample Preparation}

Dihydralazine mesylate (Nepresol Inject ${ }^{\circledR}{ }^{\circledR}$, Teofarma srl, Pavia, Italy) and metamizole sodium (Novaminsulfon-ratiopharm ${ }^{\circledR}{ }^{\circledR} 2.5 \mathrm{~g} / 5 \mathrm{~mL}$ Injektionslösung Ratiopharm $\mathrm{GmbH}$, Ulm, Germany) were diluted with $0.9 \%$ sodium chloride for injection and the drugs were mixed in infusion bags (Maco Pharma International $\mathrm{GmbH}$, Langen, Germany). Using HPLC-UV, we investigated the compatibility of dihydralazine and metamizole in the standard concentration ranges of dihydralazine $0.25-0.75 \mathrm{mg} / \mathrm{mL}$ and metamizole $(25.0-50.0 \mathrm{mg} / \mathrm{mL})$ applied at German intensive care units by combining both the high and the low limit of regular administration concentrations. We analyzed binary admixtures of dihydralazine $0.25 \mathrm{mg} / \mathrm{mL}$ and metamizole $25 \mathrm{mg} / \mathrm{mL}$, dihydralazine $0.75 \mathrm{mg} / \mathrm{mL}$ and metamizole $25 \mathrm{mg} / \mathrm{mL}$, dihydralazine $0.25 \mathrm{mg} / \mathrm{mL}$ and metamizole $50 \mathrm{mg} / \mathrm{mL}$, and dihydralazine $0.75 \mathrm{mg} / \mathrm{mL}$ and metamizole $50 \mathrm{mg} / \mathrm{mL}$. The infusion bags were stored in light-protecting bags at room temperature $\left(22-24{ }^{\circ} \mathrm{C}\right)$ due to the light sensitivity of metamizole. The experiments were conducted in duplicate with the reversed order of drug addition. Furthermore, different batches of drugs and carrier solutions were used for sample preparation, as it is recommended in international literature [8,9]. Samples were drawn at $0 \mathrm{~h}, 0.5 \mathrm{~h}, 1 \mathrm{~h}, 2 \mathrm{~h}, 4 \mathrm{~h}, 6 \mathrm{~h}$, and $24 \mathrm{~h}$ and stored at $-80{ }^{\circ} \mathrm{C}$ to prevent further reactions as the samples could not be analyzed immediately. Prior to measurement the samples were thawed at room temperature. Both drugs were also prepared as blank solutions to provide stability data (Table 1). For the HPLC-MS analysis, samples were generated with $0.75 \mathrm{mg} / \mathrm{mL}$ of dihydralazine and 0.75-50.0 mg/mL of metamizole, and analyzed at $0 \mathrm{~h}, 4 \mathrm{~h}$, and $21 \mathrm{~h}$. Samples containing less metamizole than the standard administration concentrations were analyzed to obtain valid mass spectra. As the samples were measured immediately they were stored at room temperature under light protection.

Table 1. Drug amount of admixtures and blank solutions.

\begin{tabular}{|c|c|c|c|c|c|c|c|}
\hline \multicolumn{8}{|c|}{ Time Elapsed After Mixing (h), \% Initial Concentration Remaining } \\
\hline $\begin{array}{l}\text { Drug combinations. } \\
\quad \text { nominal initial } \\
\text { concentration }(\mathrm{mg} / \mathrm{mL})\end{array}$ & 0 & 0.5 & 1 & 2 & 4 & 6 & 24 \\
\hline Metamizole $33.3 \mathrm{mg} / \mathrm{mL}$ & 100.00 & 91.79 & 92.10 & 92.40 & 92.40 & 91.49 & 91.19 \\
\hline $\begin{array}{c}\text { Dihydralazine } \\
0.75 \mathrm{mg} / \mathrm{mL} \\
\text { Metamizole } 25 \mathrm{mg} / \mathrm{mL}\end{array}$ & $\begin{array}{l}\text { immediate major decline, } \\
\qquad 100.00\end{array}$ & $\begin{array}{c}\text { not detectable, } \\
92.96 ; 89.80\end{array}$ & $\begin{array}{c}\text { not detectable, } \\
88.73 ; 86.27\end{array}$ & $\begin{array}{c}\text { not detectable, } \\
88.73 ; 85.10\end{array}$ & $\begin{array}{c}\text { not detectable, } \\
89.67 ; 83.14\end{array}$ & $\begin{array}{c}\text { not detectable, } \\
87.79 ; 82.75\end{array}$ & $\begin{array}{c}\text { not detectable, } \\
85.45 ; 81.57\end{array}$ \\
\hline $\begin{array}{c}\text { Dihydralazine } \\
0.25 \mathrm{mg} / \mathrm{mL} \\
\text { Metamizole } 50 \mathrm{mg} / \mathrm{mL}\end{array}$ & $\begin{array}{l}\text { immediate major decline, } \\
\qquad 100.00\end{array}$ & $\begin{array}{c}\text { not detectable, } \\
97.95 ; 95.78\end{array}$ & $\begin{array}{c}\text { not detectable, } \\
95.69 ; 97.11 \\
\end{array}$ & $\begin{array}{c}\text { not detectable, } \\
94.66 ; 95.11 \\
\end{array}$ & $\begin{array}{c}\text { not detectable, } \\
95.28 ; 95.33\end{array}$ & $\begin{array}{c}\text { not detectable, } \\
91.79 ; 93.33\end{array}$ & $\begin{array}{c}\text { not detectable, } \\
89.94 ; 89.78\end{array}$ \\
\hline
\end{tabular}

\subsection{HPLC-UV Analysis}

HPLC-UV analysis on the drug amount of dihydralazine and metamizole was performed using an Ultimate 3000 HPLC system (Thermo Fisher Scientific, Waltham, MA, USA). This consisted of a pump (LPG-3400SD), autosampler (WPS-3000TSL), column oven (TCC-3000SD), and a diode array detector 
(DAD-3000). The data was analyzed with Chromeleon 7.2 SR4 software (Thermo Fisher Scientific, Waltham, MA, USA).

Dihydralazine was analyzed with a Roc Cyano column $3 \mu \mathrm{m}, 150 \times 3.0 \mathrm{~mm}$ (Restek, Bad Homburg, Germany), and a mobile phase consisting of 76 parts buffer $(0.75 \mathrm{~g} / \mathrm{L}$ tetrabutylammonium bromide, and $1.44 \mathrm{~g} / \mathrm{L}$ sodium dodecyl sulfate, $\mathrm{pH} 3$ ) and 24 parts acetonitrile. The flow rate was $0.9 \mathrm{~mL} / \mathrm{min}$, the injection volume was $10 \mu \mathrm{L}$ and detection was obtained at $230 \mathrm{~nm}$. Metamizole was quantified with a Kinetex ${ }^{\circledR \circledR} 2.6 \mu \mathrm{m}$ Phenyl-Hexyl column, $150 \times 2.1 \mathrm{~mm}$, (Phenomenex, Torrance, CA, USA) and a mobile phase consisting of methanol (50 parts) and $\mathrm{K}_{2} \mathrm{HPO}_{4}$ buffer, $\mathrm{pH} 6.8$ (50 parts). Metamizole samples with a concentration of $25 \mathrm{mg} / \mathrm{mL}$ had to be diluted with $\mathrm{NaCl} 0.9 \% 1: 10$, while metamizole samples with a concentration of $50 \mathrm{mg} / \mathrm{mL}$ had to be diluted with $\mathrm{NaCl} 0.9 \%$ 1:100 to achieve valid HPLC-UV spectra. The flow rate was $0.2 \mathrm{~mL} / \mathrm{min}$, the injection volume was $5 \mu \mathrm{L}$ and detection was obtained at $254 \mathrm{~nm}$. A calibration curve was measured every day. Both HPLC-UV methods were validated according to FDA guideline Q2B "Validation of Analytical Procedures: Methodology" on specificity, linearity, reproducibility, and precision [10]. A drug amount between $90 \%$ and $110 \%$ of the original concentration was set as a specification for compatibility and stability [11].

\subsection{HPLC-MS Analysis}

The HPLC-MS analysis was conducted with a Waters Alliance e2695 Separations Module system, including a Waters 2998 photodiode array detector and a Waters ACQUITY QDa detector with a $\mathrm{m} / z$ range from 100-700 Da (Waters Corporation, Milford, MA, USA). The data was analyzed with Empower 3 software (Waters Corporation, Milford, MA, USA).

An XBridge C18 column ( $3.5 \mu \mathrm{m}, 2.1 \times 50 \mathrm{~mm}$, Waters Corporation, Milford, MA, USA) and a gradient elution with a mobile phase consisting of water ( $0.1 \%$ formic acid) and acetonitrile were used. Detection was achieved at $220 \mathrm{~nm}$ and $254 \mathrm{~nm}$.

\section{Results}

\subsection{HPLC-UV Analysis}

The dihydralazine blank solution proved to be highly stable with its content varying in a narrow range of $\pm 1 \%$ over $24 \mathrm{~h}$ (Table 1). Despite remaining within the specifications of $100 \pm 10 \%$, the drug concentration in the blank solution of metamizole dropped to approx. $92 \%$ during the initial $30 \mathrm{~min}$ and then remained constant $(92 \pm 1 \%)$ over the course of $24 \mathrm{~h}$. To analyze the compatibility of both drugs, admixtures of the high and the low range of standard administration concentration were prepared. In all admixtures of the two drugs, an immediate decrease in the concentration of dihydralazine was determined $(0 \mathrm{~h})$. Indeed, dihydralazine was no longer detectable from $30 \mathrm{~min}$ incubation time onwards. In terms of the fate of metamizole in the admixtures, the presence of dihydralazine led to an increased decomposition of metamizole depending on the relative amount of dihydralazine added. Compared to the blank solution of metamizole (decrease to ca. $92 \%$ over $24 \mathrm{~h}$ ), a low amount of added dihydralazine $(0.25 \mathrm{mg} / \mathrm{mL})$ reduced the original content of metamizole $(25 \mathrm{or} 50 \mathrm{mg} / \mathrm{mL})$ to $85-90 \%$ (after $24 \mathrm{~h}$ ), and a higher amount of dihydralazine $(0.75 \mathrm{mg} / \mathrm{mL})$ led to a further decline to $80-85 \%$ of the original metamizole concentration $(25 \mathrm{or} 50 \mathrm{mg} / \mathrm{mL})$ after $24 \mathrm{~h}$. In the investigated admixtures, the dihydralazine content was no longer consistent with specifications $(90-110 \%$ of the original amount) already after a few minutes of incubation time, while the concentration of metamizole dropped below $90 \%$ after hours, depending on the amount of dihydralazine initially added.

\subsection{HPLC-MS Analysis}

HPLC-MS analysis was conducted on admixtures of dihydralazine $(0.75 \mathrm{mg} / \mathrm{mL})$ and metamizole $(50 \mathrm{mg} / \mathrm{mL}, 7.5 \mathrm{mg} / \mathrm{mL}, 1.5 \mathrm{mg} / \mathrm{mL}$, and $0.75 \mathrm{mg} / \mathrm{mL}$ ) immediately after admixture. It was necessary to reduce the concentration of metamizole in comparison to the HPLC-UV measurements to obtain valid HPLC-MS spectra. Selected combinations were also analyzed after a reaction time of $21 \mathrm{~h}$. 
The admixture of dihydralazine $(0.75 \mathrm{mg} / \mathrm{mL})$ and metamizole $(50 \mathrm{mg} / \mathrm{mL})$ led to an immediate degradation of dihydralazine, with HPLC-MS unable to detect dihydralazine $\left(\mathrm{m} / z 191\right.$ for $\left.[\mathrm{M}+\mathrm{H}]^{+}\right)$. This was consistent with the HPLC-UV results. Instead, molecular weights of $\mathrm{m} / \mathrm{z} 203(0.8 \mathrm{~min}), \mathrm{m} / \mathrm{z} 215$ ( $0.8 \mathrm{~min})$, and $\mathrm{m} / \mathrm{z} 285$ ( $0.8 \mathrm{~min}$ ) were detected. As all decomposition products of dihydralazine eluted simultaneously, separation and quantification of the single decomposition products were not successful.

The admixture of dihydralazine $(0.75 \mathrm{mg} / \mathrm{mL})$ and metamizole $(7.5 \mathrm{mg} / \mathrm{mL})$ showed a signal at $\mathrm{m} / \mathrm{z} 218[\mathrm{M}+\mathrm{H}]^{+}(4.4 \mathrm{~min})$, caused by hydrolyzed metamizole. Signals at $\mathrm{m} / \mathrm{z} 203(0.8 \mathrm{~min})$ and $\mathrm{m} / \mathrm{z} 215$ $(0.8 \mathrm{~min})$ were assigned to reaction products of dihydralazine and metamizole. Dihydralazine could not be detected in the sample.

Admixtures of dihydralazine $(0.75 \mathrm{mg} / \mathrm{mL})$ and metamizole $(1.5 \mathrm{mg} / \mathrm{mL})$ showed a signal of dihydralazine $\mathrm{m} / \mathrm{z} 191[\mathrm{M}+\mathrm{H}]^{+}(0.51 \mathrm{~min})$ and hydrolyzed metamizole $\mathrm{m} / \mathrm{z} 218[\mathrm{M}+\mathrm{H}]^{+}(4.4 \mathrm{~min})$. As mostly undegraded dihydralazine was found, the sample was analyzed again after $21 \mathrm{~h}$ for further degradation products. Signals at $\mathrm{m} / z 203(0.8 \mathrm{~min}), \mathrm{m} / \mathrm{z} 215(0.8 \mathrm{~min})$, and $\mathrm{m} / \mathrm{z} 285(0.8 \mathrm{~min})$ could be assigned to degradation products.

The combination of dihydralazine $(0.75 \mathrm{mg} / \mathrm{mL})$ and metamizole $(0.75 \mathrm{mg} / \mathrm{mL})$ reinforced the findings of the previously analyzed admixtures. Signals of dihydralazine $m / z 191[\mathrm{M}+\mathrm{H}]^{+}(0.51 \mathrm{~min})$ and hydrolyzed metamizole $\mathrm{m} / \mathrm{z} 218[\mathrm{M}+\mathrm{H}]^{+}(4.4 \mathrm{~min})$ could be detected. After a reaction time of $21 \mathrm{~h}$, signals of dihydralazine $\mathrm{m} / \mathrm{z} 191[\mathrm{M}+\mathrm{H}]^{+}(0.51 \mathrm{~min})$ and signals at $\mathrm{m} / \mathrm{z} 203(0.8 \mathrm{~min}), \mathrm{m} / \mathrm{z} 215$ (0.8 $\mathrm{min})$, and $\mathrm{m} / \mathrm{z} 285$ (0.8 $\mathrm{min})$ were observed.

\section{Discussion}

The analyses of combinations of dihydralazine and metamizole indicate that the drugs are highly incompatible due to the considerable decrease that occurred in the quantity of dihydralazine. Our findings suggest degradation pathways, which we considered reasonable in terms of the chemical properties of dihydralazine and metamizole. Due to the high reactivity of dihydralazine and the apparent ability of metamizole to liberate formaldehyde, further incompatibilities may exist for other combinations of both drugs.

\subsection{Independent Degradation of Metamizole—Background Reaction}

As shown by the HPLC-UV analysis of the blank solution of metamizole, the concentration of the drug decreased over approx. $30 \mathrm{~min}$, until an equilibrium state was reached, after which the metamizole concentration remained unchanged. This equilibrium may have involved the formation of sulphite and formaldehyde, whereby the increased basicity of the solution caused by the conversion of the sulfonate group to sulphite may have been responsible for the equilibrium state, and, thus, for preventing a continuous degradation of metamizole (Figure 1). In agreement with this assumption, HPLC-MS analysis of the metamizole blank solution showed ions at $m / z 230[\mathrm{M}]^{+}$and $m / z 218[\mathrm{M}+\mathrm{H}]^{+}$, which can be assigned to the background reaction.

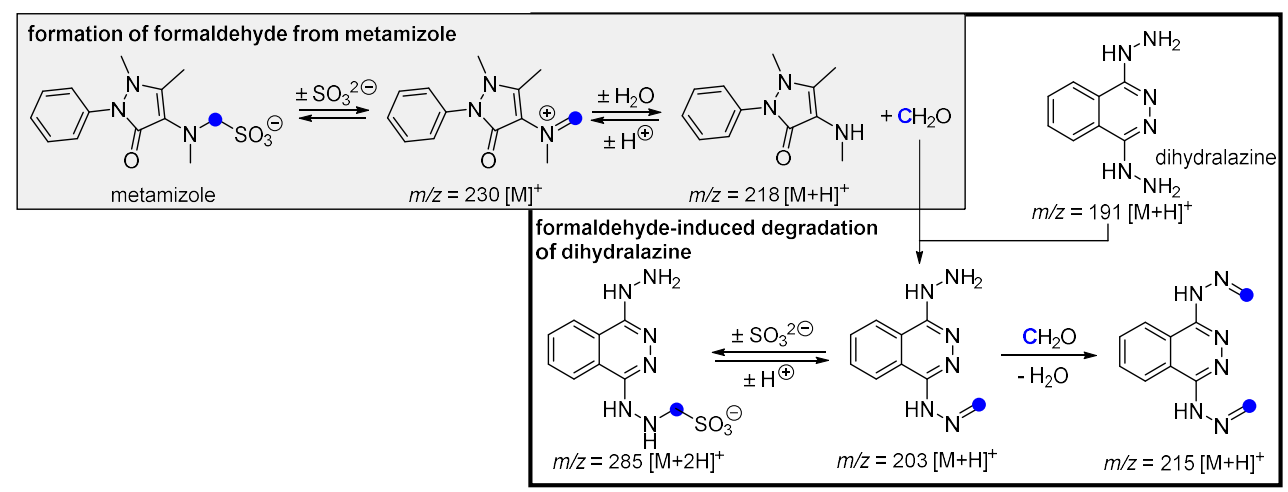

Figure 1. Liberation of formaldehyde from metamizole and formation of degradation products. The transferred carbon atom was highlighted in blue. 


\subsection{Hydrolysis of Metamizole and Degradation of Dihydralazine with Formaldehyde}

The above mentioned formation of formaldehyde from metamizole is further supported by the fast degradation of dihydralazine in admixtures (HPLC-UV) and the newly formed derivatives identified by HPLC-MS. Depending on the relative concentrations of metamizole and dihydralazine (see HPLC-MS experiments), dihydralazine $m / z 191[\mathrm{M}+\mathrm{H}]^{+}$partially remained or fully disappeared in the admixtures, and condensation products with formaldehyde arose $\left(m / z 203[\mathrm{M}+\mathrm{H}]^{+}, m / z 215\right.$ $\left.[\mathrm{M}+\mathrm{H}]^{+}\right)$. The detection of the mass $m / z 285[\mathrm{M}+\mathrm{H}]^{+}$pointed to the availability of sulphite ions in the admixtures. Since dihydralazine removes formaldehyde from the background equilibrium of metamizole, it is reasonable that higher amounts of dihydralazine led to an increased degradation of metamizole. This trend was observed in the HPLC-UV experiments (Table 1).

These findings demonstrate that dihydralazine and metamizole are highly incompatible as a result of reactions between the two drugs. If both drugs must be administered to patients, different catheter lines should be used to avoid co-administration.

Author Contributions: Conceptualization, A.K.K., O.F., S.K., M.R.H., and F.D.; methodology, A.K.K. and O.F.; software, A.K.K. and O.F.; validation, A.K.K., O.F., and S.K.; formal analysis, A.K.K., O.F.,S.K., M.R.H., and F.D.; investigation, A.K.K. and O.F.; resources, M.R.H. and F.D.; data curation, A.K.K. and O.F.; writing-original draft preparation, A.K.K. and O.F.; writing-review and editing, S.K., M.R.H., and F.D.; visualization, O.F. and M.R.H.; supervision, M.R.H. and F.D.; project administration, F.D.; funding acquisition, not applicable. All authors have read and agreed to the published version of the manuscript.

Funding: This research received no external funding.

Conflicts of Interest: Frank Dörje reports personal consulting fees from E. Lilly, personal fees for lectures from B. Braun and Sanofi outside the submitted work. Anna Katharina Koller, Oliver Fischer, Sabine Krebs, and Markus Rolf Heinrich declare that they have no conflict of interests.

\section{References}

1. Asif, M. Pharmacological activities of various phthalazine and phthalazinone derivatives. Chem. Int. 2019, 5, 97-108.

2. Del Olmo, E.; Barboza, B.; Ybarra, M.I.; López-Pérez, J.L.; Carrón, R.; Sevilla, M.A.; Boselli, C.; San Feliciano, A. Vasorelaxant activity of phthalazinones and related compounds. Bioorganic Med. Chem. Lett. 2006, 16, 2786-2790. [CrossRef] [PubMed]

3. Tissot, E.; Cornette, C.; Demoly, P.; Jacquet, M.; Barale, F.; Capellier, G. Medication errors at the administration stage in an intensive care unit. Intensive Care Med. 1999, 25, 353-359. [CrossRef] [PubMed]

4. Newton, D.W. Drug incompatibility chemistry. Am. J. Health Syst. Pharm. 2009, 66, 348-357. [CrossRef] [PubMed]

5. Kanji, S.; Lam, J.; Johanson, C.; Singh, A.; Goddard, R.; Fairbairn, J.; Lloyd, T.; Monsour, D.; Kakal, J. Systematic review of physical and chemical compatibility of commonly used medications administered by continuous infusion in intensive care units. Crit. Care Med. 2010, 38, 1890-1898. [CrossRef] [PubMed]

6. Marsilio, N.R.; da Silva, D.; Bueno, D. Drug incompatibilities in the adult intensive care unit of a university hospital. Rev. Bras. de Ter. Intensiva 2016, 28, 147. [CrossRef] [PubMed]

7. Machotka, O.; Manak, J.; Kubena, A.; Vlcek, J. Incidence of intravenous drug incompatibilities in intensive care units. Biomed. Pap. Med. Fac. Univ. Palacky Olomouc. Czech. Repub. 2015, 159, 652-656. [CrossRef] [PubMed]

8. Trissel, L.A. Avoiding Common Flaws in Stability and Compatibility Studies of Injectable Drugs; Oxford University Press: Oxford, UK, 1983.

9. Trissel, L.A.; Flora, K.P. Stability studies: Five years later. Am. J. Hosp. Pharm. 1988, 45, 1569-1571. [CrossRef] [PubMed] 
10. Research Center for Drug Evaluation and Research, Center for Biologics Evaluation and Research. Q2B Validation of Analytical Procedures: Methodology. U.S. Food \& Drug Administration, 2018. Available online: https://www.fda.gov/regulatory-information/search-fda-guidance-documents/ q2b-validation-analytical-procedures-methodology (accessed on 28 February 2020).

11. European Medicines Agency. Specifications and Control Tests on the Finished Product. Guideline 3AQ11a. 1991. Available online: https://www.ema.europa.eu/en/documents/scientific-guideline/specifications-controltests-finished-product_en.pdf (accessed on 22 April 2020).

(C) 2020 by the authors. Licensee MDPI, Basel, Switzerland. This article is an open access article distributed under the terms and conditions of the Creative Commons Attribution (CC BY) license (http://creativecommons.org/licenses/by/4.0/). 